\title{
Transanal minimally invasive surgery for total mesorectal excision (TAMIS-TME): results and experience with the first 20 patients undergoing curative-intent rectal cancer surgery at a single institution
}

\author{
S. Atallah · B. Martin-Perez • M. Albert • \\ T. deBeche-Adams • G. Nassif • L. Hunter • \\ S. Larach
}

Received: 9 September 2013/Accepted: 2 November 2013/Published online: 23 November 2013

(C) Springer-Verlag Italia 2013

\begin{abstract}
Background Transanal TME is a new approach to performing minimally invasive rectal resection. It is particularly well suited for patients with locally advanced distal rectal cancer and obesity, where the abdominal approach is challenging. Transanal TME can be performed with either TAMIS or TEM. Here, we report our initial experience with transanal TME using TAMIS (TAMIS-TME).

Methods Patients were selected to undergo transanal TME using the TAMIS platform (TAMIS-TME) primarily for malignant disease, but also for select cases of benign disease. Transanal TME defines a "bottom-up" approach to en bloc rectal cancer resection. Transanal TME requires abdominal access for proximal colonic mobilization and is often done in conjunction with a laparoscopic approach.

Results During a 32-month period, 20 patients underwent TAMIS-TME with curative intent. The primary indication for transanal TME was distal, locally advanced rectal cancer. The median age of rectal cancer patients at the time of surgery was 57 years (range 36-73 years) with $30 \%$ (6) female and $70 \%$ (14) male. The median body mass index (BMI) measured was $24 \mathrm{~kg} / \mathrm{m}^{2}$ (range $18-41 \mathrm{~kg} / \mathrm{m}^{2}$ ); this included six patients $(30 \%)$ with obesity (BMI $\geq 30 \mathrm{~kg}$ / $\mathrm{m}^{2}$ ). Mean operating time was $243 \mathrm{~min}$ (range 140-495 min) with blood loss averaging $153 \mathrm{ml}$. Postoperative length of stay averaged 4.5 days (range 3-24 days). There was no 30-day postoperative mortality. Surgical complications included wound infection $(n=2)$, pelvic abscess $(n=4)$, and prolonged ileus $(n=4)$. The anastomotic leak rate was $6.7 \%(1 / 15)$. Of the 20 patients who
\end{abstract}

S. Atallah $(\bowtie) \cdot$ B. Martin-Perez $\cdot$ M. Albert .

T. deBeche-Adams · G. Nassif - L. Hunter · S. Larach

Florida Hospital, Winter Park, FL, USA

e-mail: atallah@post.harvard.edu underwent resection, $90 \%$ (18/20) had negative margins. Pathologic grading of the TME specimen revealed that $85 \%(17 / 20)$ of transanal TME specimens were found to have "completely" or "near-completely" intact mesorectal envelopes. Data collected during the 6-month median follow-up period revealed that only one patient had developed distant metastasis. There was no locoregional recurrence in any of the patients.

Conclusions Transanal TME is a feasible method for oncologic resection of locally advanced mid- and distalrectal cancer with curative intent. It has special application for patients with obesity and anatomic constraints such as a narrow male pelvis.

Keywords Total mesorectal excision - Transanal TME - TaTME - TAMIS - TAMIS-TME ·

Rectal cancer $\cdot$ Natural orifice surgery

\section{Introduction}

Flexible and rigid transanal access platforms using transanal minimally invasive surgery (TAMIS) and transanal endoscopic microsurgery (TEM) allow for en bloc resection of the rectum, and these methods represent a new approach to performing transanal total mesorectal excision (TME) $[1,2]$. It is an attractive option for experienced surgeons, particularly for mobilization of the distal rectum in the setting of difficult pelvic anatomy. This is often referred to as the "down-to-up" or transanal-transabdominal (TATA) approach [3] that can be successfully performed using TAMIS or TEM, and both platforms appear to offer a similar resection quality [4-6]. Furthermore, each platform has been shown to be capable of providing a point of access to accomplish pure natural 
orifice transluminal endoscopic surgery (NOTES) transanal TME [7, 8], other than for completion proctectomy [9].

There are now several published case reports and small series describing transanal TME-primarily with laparoscopic assistance-and early results have been quite encouraging [10-15]. Our group has also previously described the step-by-step technique for TAMIS-TME for both ultralow anastomosis as well as abdominoperineal resection [2]. We now report our initial results for 20 consecutive patients who underwent transanal TME for malignant disease.

\section{Materials and methods}

Twenty-three patients were selected to undergo transanal TME using the TAMIS platform (TAMIS-TME) during a 32-month period at a tertiary referral hospital. Three patients were excluded from further study as these resections were completed for benign disease, namely ulcerative colitis. Selection criterion included (a) locally advanced rectal cancer of the middle and distal rectum as well as (b) distal rectal cancer in combination with obesity and anatomic constraints such as a narrow male pelvis. The operations were performed by 4 colorectal surgeons experienced with TAMIS. Each patient gave special consent to undergo TAMIS-TME, and the approach of transanal TME had been approved by our institution review committee. An internal review board approved the retrospective review of prospectively gathered data on transanal TME. For the purpose of this study, Transanal TME is defined as a "bottom-up" approach to en bloc rectal cancer resection. Unlike pure NOTES, transanal TME requires a combined abdominal approach for proximal colonic mobilization and for initiation of the medial to lateral approach, as well as construction of a diverting or permanent stoma. Exceptions include completion proctectomy of a short rectal remnant, where an abdominal approach is not required [9].

\section{Surgical technique}

Transanal TME using the TAMIS platform is defined as TAMIS-TME. The technique for TAMIS-TME has been described by our group previously and is published elsewhere [2]. Briefly, TAMIS-TME is a combined technique of a transanal and abdominal approaches for TME. The abdominal portion of the operation is first completed (laparoscopic, robotic-assisted, hand-assisted, or with an open approach), including mobilization of the splenic flexure, high ligation of the inferior mesenteric artery, and division of the descending colon. The fecal stream is diverted with a loop ileostomy, unless a permanent stoma is being fashioned. These steps of the operation are always completed via an abdominal approach at our center. Selection of the abdominal approach (e,g., laparoscopic or open) is dependent on case complexity, tumor stage, and the extent of resection required. At our center, surgeon preference determines whether robotic or laparoscopic abdominal approaches are used, and there are no specific selection criterion which define whether or not one approach should be used over the other.

Once the abdominal portion has been completed, transanal TME can be performed. It is also feasible to begin the operation with the transanal TME prior to entering the abdomen. Pure NOTES is not performed.

To perform transanal TME using TAMIS, the patient is placed in the dorsal lithotomy position. A GelPOINT ${ }^{\circledR}$ Path Transanal Access Platform (Applied Medical, Inc. Rancho Santa Margarita, CA, USA) or a SILS ${ }^{\mathrm{TM}}$ Port (Mansfield, MA, USA) may be used for TAMIS access. For low-lying tumors, an intersphincteric dissection is started prior to admission of a TAMIS port, and this is done under direct vision using an anorectal retractor and electrocautery. The rectal lumen is purse-stringed closed with prolene suture. This allows for complete division of the rectum distal to the lesion, with a known [negative] distal margin. The port is then introduced, and transanal TME is performed. Typically, the operation is completed with a hand-sewn coloanal anastamosis. However, for higher lesions, the TAMIS port is introduced first, and the purse-string suture can be performed more proximally. With the TAMIS port in place and pneumorectum established, the rectal wall is then divided just distal to the purse-string using cautery. This allows for a higher anastomosis, which can be performed using a circular stapler to construct an end-to-end anastomosis or, alternately, a low-rectal-to-colonic J-pouch anastomosis.

\section{Results}

During a 32-month period (November, 2010-August, 2013), 23 patients underwent TAMIS-TME. The majority of cases were completed in the latter 24 months (Fig. 1). The primary indication for transanal TME was distal, locally advanced rectal cancer in the majority of cases (20/ 23). Three TAMIS-TME cases were performed for inflammatory bowel disease and were excluded from the study group.

The median age of patients at the time of surgery was 57 years (range 36-73 years) with $30 \%$ (6) female and $70 \%$ (14) male (Table 1). The median body mass index (BMI) was $24 \mathrm{~kg} / \mathrm{m}^{2}$ (range $18-41 \mathrm{~kg} / \mathrm{m}^{2}$ ); this included 6 patients $(30 \%)$ with obesity, defined as BMI $\geq 30 \mathrm{~kg} / \mathrm{m}^{2}$. Mean operating time was $243 \mathrm{~min}$ (range 140-495 min) 


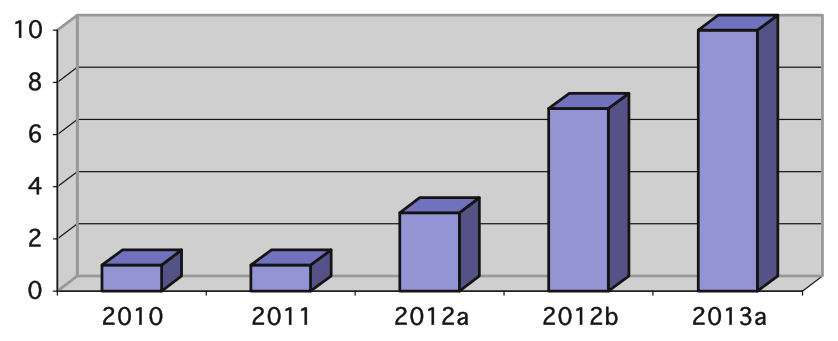

$\boldsymbol{a}$ : first half of the year; $\boldsymbol{b}$ : second half of the year

Fig. 1 Number of transanal TME cases performed at our center by year. a First half of the year; $\mathbf{b}$ second half of the year

Table 1 Patient characteristics for patients who underwent TAMISTME with curative intent for rectal cancer $(n=20)$

\begin{tabular}{ll}
\hline Characteristic & Value \\
\hline$n$ & 20 \\
Age $^{\mathrm{a}}$ & $57(36-73)$ \\
Gender & \\
Male & $14(70 \%)$ \\
Female & $6(30 \%)$ \\
BMI $\left(\mathrm{kg} / \mathrm{m}^{2}\right)^{\mathrm{a}}$ & $24(18-41)$ \\
ASA & \\
I-II & $14(70 \%)$ \\
III-IV & $6(30 \%)$ \\
\hline
\end{tabular}

$n$ total number of cases, $B M I$ body mass index $\left(\mathrm{kg} / \mathrm{m}^{2}\right), A S A$ American Society of Anesthesiologists risk score

${ }^{\text {a }}$ Values reported as median (range)

with blood loss averaging $153 \mathrm{ml}$ (range $30-500 \mathrm{ml}$ ). Postoperative length of stay averaged 4.5 days (range 3-24 days) [Table 2].

Seventy-five percent $(15 / 20)$ of patients were candidates for reanastomosis after transanal TME. All but one patient had a defunctionalizing loop ileostomy constructed. The majority of the anastomoses were straight, hand-sewn coloanal $(n=11)$; one was performed using an end-to-end anastomotic (EEA) stapling device. In the remaining cases $(n=3)$, an EEA device was used to construct a colonic-Jpouch-to-low-rectal anastomosis (Table 2).

There were no intraoperative complications, and there was no 30-day postoperative mortality. One patient, however, died suddenly, without prodrome 8 weeks after TAMIS-TME. The cause of death was determined to be acute pulmonary embolism. Postoperative surgical complications included wound infection $(n=2)$, pelvic abscess $(n=4)$, prolonged ileus $(n=4)$, and anastomotic leak $(n=1)$ (Table 2). All were managed conservatively and resolved without sequelae, except the anastomotic leak which necessitated re-operation with takedown of the coloanal anastomosis and construction of a permanent end colostomy. This anastomotic disruption was secondary to
Table 2 Intraoperative and postoperative characteristics of 20 consecutive patients who underwent transanal TME using the TAMIS approach

\begin{tabular}{|c|c|}
\hline Characteristic & Value \\
\hline \multicolumn{2}{|l|}{ Approach $^{\mathrm{c}}$} \\
\hline Open + TAMIS-TME & 3 \\
\hline Laparoscopic + TAMIS-TME ${ }^{\mathrm{e}}$ & 11 \\
\hline Robotic-assisted + TAMIS-TME ${ }^{\mathrm{d}}$ & 6 \\
\hline \multicolumn{2}{|l|}{ Anastomosis } \\
\hline Coloanal—straight, hand sewn & 11 \\
\hline Coloanal—straight with stapled 29-mm EEA device & 1 \\
\hline $\begin{array}{l}\text { Coloanal with colonic J-pouch (with stapled 29-mm } \\
\text { EEA device) }\end{array}$ & 3 \\
\hline None-end ileostomy & 2 \\
\hline None-end colostomy & 3 \\
\hline Operating time $(\min )^{\mathrm{a}}$ & $\begin{array}{l}243 \\
(140-495)\end{array}$ \\
\hline Diversion (loop ileostomy) ${ }^{\mathrm{a}}$ & $14(93 \%)$ \\
\hline $\operatorname{EBL}(\mathrm{ml})^{\mathrm{a}}$ & $\begin{array}{l}153 \\
(30-500)\end{array}$ \\
\hline $\operatorname{LOS}\left(\right.$ days) ${ }^{\mathrm{a}}$ & $4.5(3-24)$ \\
\hline \multicolumn{2}{|l|}{ Morbidity $(n)$} \\
\hline \multicolumn{2}{|l|}{ Early morbidity } \\
\hline Wound infection & 2 \\
\hline Pelvic abscess & 4 \\
\hline Prolonged ileus & 4 \\
\hline Pneumonia & 1 \\
\hline Acute renal failure & 1 \\
\hline Anastomotic leak & 1 \\
\hline \multicolumn{2}{|l|}{ Late morbidity } \\
\hline Peri-anastomotic fluid collections & 2 \\
\hline Anastomotic strictures ${ }^{\mathrm{b}}$ & 4 \\
\hline
\end{tabular}

$E B L$ estimated blood loss, EEA end-to-end anastomotic stapling device, $L O S$ postoperative length of stay as measured in days

${ }^{a}$ Values reported as mediant (range)

b Subclinical stricturing noted on physical exam, patients asymptomatic

c Denotes which method was used for the abdominal portion of the operation, as well as variations in the approach to transanal TME. In all but the first two transanal TME cases, the GelPOINT ${ }^{\circledR}$ Path access platform (Applied Medical, Inc.) was used. The first two cases were performed using a SILS ${ }^{\mathrm{TM}}$ Port (Covidien)

d This includes one case in which robotic-assisted transanal surgery was performed (RATS-TME)

e Includes one patient who had TAMIS-assisted APR

ischemia, most likely secondary to disruption of the blood supply to the proximal limb (e.g., descending colon). Therefore, the anastomotic leak rate was determined to be $6.7 \%$ ( 1 out of the 15 patients who underwent anastomosis). The morbidity profile and variations in operative approaches are detailed in Table 2 . 
Table 3 Tumor characteristics of patients who underwent TAMISTME with curative intent for rectal cancer $(n=20)$

\begin{tabular}{|c|c|}
\hline Characteristic & Value \\
\hline Distance from anal verge $(\mathrm{cm})^{\mathrm{a}}$ & $5(1-9)$ \\
\hline Tumor size $(\mathrm{cm})^{\mathrm{a}}$ & $3.5(0.6-9.3)$ \\
\hline \multicolumn{2}{|l|}{ Tumor location } \\
\hline Circumferential & 3 \\
\hline Anterior & 7 \\
\hline Anterolateral & 5 \\
\hline Posterior & 2 \\
\hline Posterolateral & 3 \\
\hline \multicolumn{2}{|l|}{ cTNM } \\
\hline Stage I & $2(10 \%)$ \\
\hline Stage II & $3(15 \%)$ \\
\hline Stage III & $15(75 \%)$ \\
\hline \multicolumn{2}{|l|}{ TNM } \\
\hline Stage 0 & $5(25 \%)$ \\
\hline Stage I & $3(15 \%)$ \\
\hline Stage II & $6(30 \%)$ \\
\hline Stage III & $5(25 \%)$ \\
\hline Stage IV & $1(5 \%)$ \\
\hline \multicolumn{2}{|l|}{ TME grading } \\
\hline Quirke 3 & $11(55 \%)$ \\
\hline Quirke 2 & $6(30 \%)$ \\
\hline Quirke 1 & $2(10 \%)$ \\
\hline Unknown & $1(5 \%)$ \\
\hline Lymph node harvest ${ }^{\mathrm{a}}$ & $22.5(9-51)$ \\
\hline Neoadjuvant treatment & $17(85 \%)$ \\
\hline
\end{tabular}

cTNM clinical preoperative stage, TNM pathologic postoperative stage, $T M E$ quality of mesorectal envelope as graded by pathologist

a Median (range)

Tumor characteristics and quality of oncologic resection for the 20 patients undergoing TAMIS-TME with curative intent is shown in Table 3. The tumor's median distance from the anal verge measured $5 \mathrm{~cm}$ (range $1-9 \mathrm{~cm}$ ) with 12 lesions positioned anterior or anterolateral, 5 posterior or posterolateral, and 3 circumferential. The median tumor diameter was $3.5 \mathrm{~cm}$ (range $0.6-9.3 \mathrm{~cm}$ ). The median number of lymph nodes harvested with transanal TME was 22.5 (range 9-51 nodes). Nodal harvest for patients with an underlying diagnosis of malignancy was $\geq 12$ in $75 \%$ (15/ $20)$, and of these patients, $80 \%(12 / 15)$ had neoadjuvant chemoradiation. For patients with $\leq 12$ nodes (range 9-11 nodes) harvested, all had received neoadjuvant chemoradiation (Table 4).

Of the patients who underwent resection for cancer, $90 \%(18 / 20)$ had negative margins. Any margin $\leq 2 \mathrm{~mm}$ was considered a positive margin. Based on this criteria, there were 2 TAMIS-TME cases with positive margins: one patient had a 1-mm distal margin in a rectal tumor that encroached on the anal canal, and another patient had a 1-mm circumferential resection margin (CRM) (Table 4).

Macroscopic pathologic grading of the TME specimen, including cross-sectional analysis, was done for all but one (19/20) patient who underwent TAMIS-TME with curative intent for rectal cancer. In the single case $(1 / 20)$ in which the TME was not formally graded, it was noted by the pathologist that the mesorectal envelope "appeared to be intact." However, macroscopic, cross-sectional examination was not performed, and therefore, the specimen was not properly evaluated. For this reason, the TME quality for this resection could not be determined. The analysis showed that $89.5 \%(17 / 19)$ of transanal TME surgical specimens were graded as "completely intact" (Quirke 3) or "near-completely" (Quirke 2) intact mesorectal envelopes by a gastrointestinal (GI) pathologist. Only 2 out of 19 specimens $(10.5 \%)$ of graded specimens revealed an incomplete mesorectal envelope, due to defects $\geq 5 \mathrm{~mm}$ in the mesorectal envelope. In these 2 cases, the resection margins-distal and circumferential-were negative. Surgical specimen quality is detailed in Table 4.

Follow-up data revealed that there was 1 patient who developed distant metastasis. This occurred 9 months after surgery in case \#4 (Table 4). Pathology for this patient who underwent TAMIS-TME revealed well-differentiated adenocarcinoma, staged ypT3N0. In this case, 0/17 lymph nodes were harvested and the mesorectal envelope was completely intact (Quirke 3). This patient did not have postoperative chemotherapy due to severe toxicity during neoadjuvant therapy. He successfully underwent curativeintent liver resection and remains under close surveillance. There were no other cases of recurrence detected during the study's 6-month median follow-up period (range 1-24 months).

Ileostomy closure was performed within the first 3 months after TAMIS-TME in $64 \%(9 / 14)$ of patients who underwent diversion of the fecal stream. The remaining (5/14) were closed within 1 year. The principle reason for delay in ileostomy closure was the recommendation to start adjuvant chemotherapy without delay, and in selected cases, ileostomy reversal was postponed until adjuvant chemotherapy was completed and restaging workup revealed no evidence of disease recurrence. A telephone survey was conducted to assess fecal continence 8 weeks after ileostomy closure. Most patients stated they had mild fecal incontinence defined as less than one accident per day. One patient (case\#4, Table 4) reported lifestyle-limiting incontinence, Cleveland Cinic Florida (Wexner) Fecal Incontinence Score 16, and this has not improved 12 months post-resection [16].

During the follow-up period, anoscopy, rigid proctosigmoidoscopy, and digital rectal examination were performed every 3 months. Physical examination revealed that 
Table 4 Diagnosis and pathologic characteristics of 20 consecutive patients who underwent transanal TME (TAMIS-TME) for malignant disease

\begin{tabular}{|c|c|c|c|c|c|c|c|c|c|c|c|}
\hline$n$ & $\mathrm{G}$ & BMI & Diagnosis $^{a}$ & CRT & cTNM & TNM & DV & Dia. & TME & LN & MAR \\
\hline 1 & $\mathrm{M}$ & 37 & Rectal adenocarcinoma $^{\mathrm{b}}$ & Yes & T3N1 & урT0NO & 7 & 4.5 & Complete & $0 / 29$ & Neg \\
\hline 2 & $\mathrm{~F}$ & 31 & Squamous cell adenocarcinoma & Yes & T4NX & ypTON0 & 8 & 7.6 & Complete & $0 / 21$ & $\mathrm{Neg}$ \\
\hline 3 & $\mathrm{~F}$ & 18 & $\begin{array}{l}\text { Low-grade (moderately differentiated) } \\
\text { adenocarcinoma }\end{array}$ & Yes & T3N0 & ypT2N0 & 2 & 4 & Complete & $0 / 42$ & Neg \\
\hline 4 & M & 35 & Low-grade (well differentiated) adenocarcinoma & Yes & T3N1 & урT3N0 & 5 & 1.5 & Complete & $0 / 17$ & Neg \\
\hline 5 & $\mathrm{~F}$ & 18 & $\begin{array}{l}\text { Low-grade (moderately differentiated) } \\
\text { adenocarcinoma }\end{array}$ & Yes & T4N0 & ypT4N0 & 5 & 3.5 & Complete & $0 / 9$ & $\mathrm{Neg}$ \\
\hline 6 & M & 27 & $\begin{array}{l}\text { Low-grade (moderately differentiated) } \\
\text { adenocarcinoma }\end{array}$ & Yes & T4N2 & ypT3N1b & 4 & 1.1 & Complete & $2 / 11$ & Neg \\
\hline 7 & M & 20 & Invasive adenocarcinoma & Yes & T3N2 & ypTONO & 1 & 3 & Complete & $0 / 23$ & Neg \\
\hline 8 & M & 24 & $\begin{array}{l}\text { Low-grade (moderately differentiated) } \\
\text { adenocarcinoma }\end{array}$ & No & $\mathrm{T} 4 \mathrm{~N} 2$ & T4N0 & 6 & 9 & Unknown $^{c}$ & $0 / 14$ & $\mathrm{Neg}$ \\
\hline 9 & $\mathrm{M}$ & 22 & $\begin{array}{l}\text { Low-grade (moderately differentiated) } \\
\text { adenocarcinoma }\end{array}$ & No & T2NO & T3N0 & 5 & 2.5 & Complete & $0 / 19$ & Neg \\
\hline 10 & $\mathrm{M}$ & 22 & Rectal adenocarcinoma & Yes & $\mathrm{T} 2 \mathrm{~N} 2$ & урT0NO & 4 & 3.5 & Complete & $0 / 22$ & Neg \\
\hline 11 & M & 21 & Invasive mucinous adenocarcinoma & Yes & $\mathrm{T} 3 \mathrm{~N} 2$ & ypT3N2b & 1.2 & 3.5 & $\begin{array}{l}\text { Nearly } \\
\text { complete }\end{array}$ & $\begin{array}{c}10 / \\
15\end{array}$ & $\operatorname{Pos}^{\mathrm{d}}$ \\
\hline 12 & $\mathrm{M}$ & 32 & Mucinous adenocarcinoma & Yes & T3N1 & урT3N1b & 4 & 3 & $\begin{array}{l}\text { Nearly } \\
\text { complete }\end{array}$ & $3 / 9$ & $\mathrm{Neg}$ \\
\hline 13 & $\mathrm{~F}$ & 36 & $\begin{array}{l}\text { Low-grade (moderately differentiated) } \\
\text { adenocarcinoma }\end{array}$ & Yes & T4N1 & ypT2N0 & 1 & 3.4 & $\begin{array}{l}\text { Nearly } \\
\text { complete }\end{array}$ & $0 / 35$ & $\mathrm{Neg}$ \\
\hline 14 & M & 23 & $\begin{array}{l}\text { Low-grade (moderately differentiated) } \\
\text { adenocarcinoma }\end{array}$ & Yes & T3N2 & ypT3N2b & 2 & 9.3 & $\begin{array}{l}\text { Nearly } \\
\text { complete }\end{array}$ & $9 / 11$ & $\operatorname{Pos}^{\mathrm{e}}$ \\
\hline 15 & M & 24 & $\begin{array}{l}\text { Low-grade (moderately differentiated) } \\
\text { adenocarcinoma }\end{array}$ & Yes & T3N2 & ypT3N2aM1a & 3.5 & 4 & Complete & $3 / 32$ & Neg \\
\hline 16 & M & 41 & $\begin{array}{l}\text { Low-grade (moderately differentiated) } \\
\text { adenocarcinoma }\end{array}$ & Yes & $\mathrm{T} 3 \mathrm{~N} 1$ & ypT3N0 & 9 & 4.5 & $\begin{array}{l}\text { Nearly } \\
\text { complete }\end{array}$ & $0 / 24$ & Neg \\
\hline 17 & M & 21 & $\begin{array}{l}\text { Low-grade (moderately differentiated) } \\
\text { adenocarcinoma }\end{array}$ & Yes & $\mathrm{T} 3 \mathrm{~N} 1$ & ypT3N0 & 7 & 5 & Incomplete & $0 / 19$ & Neg \\
\hline 18 & $\mathrm{~F}$ & 19 & Rectal adenocarcinoma on tubulovillous polyp & No & T2NO & T0N2a & 5 & 1.8 & Incomplete & $5 / 51$ & Neg \\
\hline 19 & $\mathrm{~F}$ & 25 & Invasive adenocarcinoma $^{\mathrm{b}}$ & Yes & T3N1 & ypTONO & 4 & 4 & $\begin{array}{l}\text { Nearly } \\
\text { complete }\end{array}$ & $0 / 35$ & Neg \\
\hline 20 & M & 27 & $\begin{array}{l}\text { Low-grade (moderately differentiated) } \\
\text { adenocarcinoma }\end{array}$ & Yes & T3N1 & ypT2N0 & 7 & 0.6 & Complete & $0 / 11$ & Neg \\
\hline
\end{tabular}

$n$ patient case number, $G$ gender, $B M I$ body mass index $\left(\mathrm{kg} / \mathrm{m}^{2}\right), C R T$ neoadjuvant chemoradiation, $c T N M$ preoperative stage, $T N M$ postoperative stage, $D V$ distal most extent of tumor from anal verge $(\mathrm{cm})$, Dia. diameter of tumor $(\mathrm{cm}), T M E$ quality of mesorectal envelope as graded by pathologist, $L N$ number of lymph nodes harvested, denoting fraction positive (+/total), MAR surgical margins, including distal and circumferential, N/A not applicable

${ }^{a}$ Denotes final, post-resection pathology unless otherwise stated

b Pathology based on initial endoscopic biopsy, in these cases, final pathology revealed complete sterilization

c Unknown TME: The surgical specimen did not undergo proper pathologic assessment and the status of the TME could not be determined

d 1-mm distal margin

e 1-mm circumferential resection margin

4 patients had mild anastomotic strictures that were amenable to manual dilation. These were subclinical anastomotic strictures; operative intervention was not required. All 4 patients were asymptomatic.

The subset evaluation of 6 patients with obesity, definded as BMI $\geq 30 \mathrm{~kg} / \mathrm{m}^{2}$ (Table 5), revealed that all specimens were resected with negative distal and radial margins, intact TME, and a median lymph node harvest of 22.5. In this subset of patients, all transanal TME procedures were performed for the diagnosis of locally advanced mid- or distal-rectal cancer, and each patient treated had undergone neoadjuvant chemoradiation.

\section{Discussion}

TAMIS has proven to be of benefit for local excision of rectal neoplasia [4], and its versatility offers multiple applications beyond local excision [15], permitting an interface with ordinary laparoscopic, endoscopic [17, 18], or even robotic devices [19-24]. However, perhaps its most important application beyond local excision is transanal TME (TAMIS-TME). Transanal TME is a promising new approach to facilitate distal rectal mobilization, and thus represents an important area of innovation in rectal cancer surgery $[1,25]$. Other pseudonyms have also been used to 
Table 5 Patient characteristics and operative outcomes for transanal TME (TAMIS-TME) in a subset of patients with BMI $\geq 30 \mathrm{~kg} / \mathrm{m}^{2}$

\begin{tabular}{|c|c|c|c|c|c|c|c|c|c|c|c|c|c|c|c|}
\hline Case\# & Age & $\mathrm{G}$ & BMI & OT & EBL & LOS & Diagnosis & CRT & cTNM & TNM & DV & SIZE & TME & $\mathrm{LN}$ & MAR \\
\hline 1 & 59 & M & 37 & 245 & 300 & 9 & Low-grade adenoCA & Yes & T3N1 & ypT0N0 & 7 & 4.5 & Complete & $0 / 29$ & $\mathrm{Neg}$ \\
\hline 2 & 44 & $\mathrm{~F}$ & 31 & 450 & 200 & 5 & $\begin{array}{l}\text { Squamous cell } \\
\text { carcinoma }^{\mathrm{a}}\end{array}$ & Yes & T4NX & ypTONO & 8 & 7.6 & Complete & $0 / 21$ & $\mathrm{Neg}$ \\
\hline 4 & 49 & M & 35 & 210 & 100 & 3 & Low-grade adenoCA & Yes & T3N1 & ypT3N0 & 5 & 1.5 & Complete & $0 / 17$ & Neg \\
\hline 12 & 44 & M & 32 & 160 & 50 & 4 & Mucinous adenoCA & Yes & T3N1 & ypT3N1b & 4 & 3.0 & $\begin{array}{l}\text { Nearly } \\
\text { complete }\end{array}$ & $3 / 9$ & $\mathrm{Neg}$ \\
\hline 13 & 51 & $\mathrm{~F}$ & 36 & 380 & 200 & 4 & Low-grade adenoCA & Yes & T4N1b & ypT2N0 & 1 & 3.4 & $\begin{array}{l}\text { Nearly } \\
\text { complete }\end{array}$ & $0 / 35$ & Neg \\
\hline 16 & 69 & M & 41 & 255 & 250 & 8 & Low-grade adenoCA & Yes & T3N1 & урT3N0 & 9 & 4.5 & $\begin{array}{l}\text { Nearly } \\
\text { complete }\end{array}$ & $0 / 24$ & $\mathrm{Neg}$ \\
\hline$m$ & 50 & & 35.5 & 250 & 200 & 4.5 & & & & & 6 & 4.5 & & 22.5 & \\
\hline
\end{tabular}

$G$ gender, $B M I$ body mass index $\left(\mathrm{kg} / \mathrm{m}^{2}\right)$, $O T$ operating time, $E B L$ estimated blood loss $(\mathrm{ml})$, $L O S$ length of stay (days), $C R T$ neoadjuvant chemoradiation, $C T N M$ preoperative, clinical stage, TNM postoperative, pathologic stage, $D V$ distal most extent of tumor from anal verge, $T M E$ pathologist's grading of mesorectal envelop, $L N$ lymph node harvest, including fraction positive for metastasis $(+\mathrm{LN} /$ total $\mathrm{LN})$, MAR surgical margins, including distal and circumferential, $m$ median, AdenoCA Adenocarcinoma

a Vaginal squamous cell primary invading anterior rectal wall

describe transanal TME, most notably "transanal NOTES" and transanal endoscopic surgery (TES). However, these terms are somewhat confusing as transanal TME is not (as yet) a true NOTES procedure and it is not "endoscopic" either as the operation is performed outside of the rectal lumen.

Transanal TME is currently in its infancy, and in 2013, there are only $n=72$ (human and cadaveric) cases which have been published in reports and small series worldwide [26]. The overall results have been quite encouraging, though - as in the case of any new technique-this new method should be approached with caution. Appropriate experience, training, and surgeon skill are required.

Here, we report our short-term results in a retrospective review of the first 20 patients who underwent transanal TME using the flexible TAMIS platform over a 32-month period. Oncologic data reveal that transanal TME using the TAMIS approach results in high-quality resections, and in this study, $89.5 \%$ of specimens of rectal resections revealed completely or near-completely intact mesorectal envelopes. It is permissible to group these categories (complete and near-complete) together because data reveal that there is no significant difference between clinical outcome in these 2 subsets of TME-graded specimens, assuming radial and distal margins are negative [27].

Most early series and case reports on transanal TME report excellent results with regard to resection quality with negative margins and intact mesorectal envelopes [25, 26]. In our series, proper evaluation of the mesorectal envelope by an independent and experienced GI pathologist was mandatory in assessing TME quality, using the same standards set by the Dutch TME and CLASSIC trials [28,
29]. This included cross-sectional analysis of the fresh, macroscopic specimen in addition to assessing the gross specimen for the smoothness of the mesorectal envelope using methods standardized by GI pathologists [30]. Strict criteria for evaluating the mesorectal envelope were adhered to in this study, and margins were considered positive if they were $\leq 2 \mathrm{~mm}$. This is based on established data that reveal that circumferential margins $\leq 2 \mathrm{~mm}$ exhibit clinical behavior similar to grossly positive margins [31]. Hence, in this study, one patient with 1-mm CRM was classified as having a positive margin. In this case, the lesion was a bulky $9.3-\mathrm{cm}$ distal rectal tumor that exhibited a poor response to neoadjuvant treatment. The second patient had a 1-mm distal margin in a tumor $1 \mathrm{~cm}$ proximal to the dentate line. This patient is in a program of intense surveillance with proctoscopy, examination, and carcinoembryonic antigen (CEA) testing every 2 months. At 10-month follow-up, he remains disease free.

It is reasonable to assume that even expert pelvic surgeons will have some fraction of TME specimens which are not completely intact. The transanal approach may help minimize this and, in turn, could improve clinical outcomes as an incomplete TME has been shown to be an independent factor leading to diminished locoregional control, regardless as to whether or not negative margins (including CRM) are achieved [27]. Furthermore, the likelihood of locoregional recurrence with an intact mesorectal envelope, even with node-positive disease, is significantly lower than would otherwise be predicted, and this has been shown to be as low as $7.5 \%$ [32]. Thus, achieving resection with an intact mesorectal envelope is paramount, especially for low-lying rectal cancers where the risk of local recurrence is higher 
[30]. One plausible explanation for this may be that tumor deposits in the mesorectum can be discontinuous in nearly $60 \%$ of specimens, and tumor spread often occurs in the outer one-third of the envelope [33]. In this series, the average lymph node harvest, including patients treated with neoadjuvant external beam radiotherapy, was 22.5 lymph nodes, and $75 \%$ of specimens had $\geq 12$ lymph nodes. All patients with malignancy who had $<12$ lymph nodes harvested had received neoadjuvant chemoradiation (longcourse, 54 cGy external beam radiotherapy). This fits with known data which predicts a lower-than-expected lymph node harvest post-treatment $[34,35]$.

Perhaps the greatest advantage of transanal TME applies to the most difficult of all rectal cancer patients: namely, those with locally advanced distal tumors and anatomic constraints imposed by obesity and a narrow pelvis. The reason for this is that transanal access offers an in-line vantage point to the distal rectum, and with the aid of a gastight seal and pneumo-dissection, the "holy plane" for TME dissection is greatly simplified. This fundamental advantage has been highlighted by our group [2,25] and Rouanet et al. [12] who have described excellent outcomes in 8 male patients with a BMI $\geq 30 \mathrm{~kg} / \mathrm{m}^{2}$. It is in this context that the transanal approach to TME allows for improved access to the distal rectum with significantly improved visualization and dissection, making it possible to perform a precise dissection, particularly of the distal portion of the mesorectal envelope. In our series, 6 obese patients (BMI $\geq 30$ $\mathrm{kg} / \mathrm{m}^{2}$ ) underwent transanal TME using the TAMIS platform. Data from this subset of patients revealed completely/ near-completely intact mesorectal envelopes with negative margins in all cases, thereby supporting the use of transanal TME in the obese population.

Typically, morbidity and oncologic outcomes are predicted to be less favorable for tumors of the distal one-third of the rectum [36]. For this subset of operations, the 30-day morbidity is typically $30 \%$ or higher [37]. Morbidity was significant in our small series, but there was no intraoperative morbidity, and the incidence of complication requiring re-intervention (i.e., anastomotic leak) was $6.7 \%-1 /$ 15 patients who underwent TAMIS-TME with anastomosis. This result compares favorably to the anastomotic leak rate recorded in other series [38, 39].

Short-term oncologic outcomes with TAMIS-TME revealed that 1 out of 19 patients had evidence of recurrence (metastatic liver disease). This occurred despite pathology which demonstrated negative margins and a completely intact mesorectal envelope with final pathology revealing nodenegative $(0 / 17)$ disease. However, this patient was not eligible to receive adjuvant chemotherapy due to grade III toxicity encountered during neoadjuvant therapy. In this case, he represented with a solitary liver metastasis which was resected for cure, and he remains disease free at 5-month follow-up.
Transanal TME requires prerequisite training in advanced colorectal surgery, minimally invasive approaches, and dedicated experience using advanced transanal platforms, such as TEM, transanal endoscopic operation (TEO), or TAMIS. These platforms, coupled with minimally invasive approaches described here, can result in excellent oncologic outcomes. However, there is a potential risk to have worse outcomes, if the operating surgeon is not adequately trained. To date, formal training for transanal TME has not been established, and this will be necessary before the technique can be recommended for more general use.

Our study is limited by its retrospective nature, small number of patients, and short-term follow-up.

\section{Conclusions}

Transanal TME is an important application of the versatile TAMIS platform. TAMIS-TME is a feasible method for oncologic resection of locally advanced mid- and distal rectal cancer with curative intent. It has special applications for patients with obesity and anatomic constraints such as a narrow male pelvis. The same methods used in transanal TME for rectal cancer can also be effectively applied for benign disease, such as ulcerative colitis. Pathologist-led grading of the TME specimen is necessary for proper evaluation of the resection quality and should be performed routinely. Though initial results are promising, long-term data are required to determine the full utility of transanal TME. Finally, the appropriate training paradigm for transanal TME has yet to be established and this is strongly encouraged prior to widespread adoption of this technique.

Conflict of interest None.

\section{References}

1. Heald RJ (2013) A new solution to some old problems: transanal TME. Tech Coloproctol 17:257-258

2. Atallah S, Albert M, Debeche-Adams T, Nassif G, Polavarapu H, Larach S (2013) Transanal minimally invasive surgery for total mesorectal excision (TAMIS-TME): a stepwise description of the surgical technique with video demonstration. Tech Coloproctol 17:321-325

3. Marks GJ, Marks JH, Mohiuddin M, Brady L (1998) Radical Sphincter preservation surgery with coloanal anastomosis following high-dose external irradiation for the very low lying rectal cancer. Recent Results Cancer Res 146:161-174

4. Albert M, Atallah S, DeBeche-Adams T, Izfar S, Larach S (2013) Transanal minimally invasive surgery (TAMIS) for local excision of benign neoplasms and earl-stage rectal cancer: efficacy and outcomes in the first 50 patients. Dis Colon Rectum 56:301-307

5. Moore JS, Cataldo PA, Osler T, Hyman NH (2008) Transanal endoscopic microsurgery is more effective than traditional 
transanal excision for resection of rectal masses. Dis Colon Rectum 51:1026-1030

6. Christoforidis D, Cho HM, Dixon MR, Mellgren AF, Madoff RD, Finne C (2009) Transanal endoscopic microsurgery versus conventional transanal excision for patients with early rectal cancer. Ann Surg 249:776-782

7. Zhang H, Zhang YS, Jin XW, Li MZ, Fan JS, Yang ZH (2013) Transanal single-port laparoscopic total mesorectal excision in the treatment of rectal cancer. Tech Coloproctol 17:117-123

8. Leroy J, Barry BD, Melani A, Mutter D, Marescaux J (2012) Noscar transanal total mesorectal excision: the last step to pure NOTES for colorectal surgery. Arch Surg 19:1-5

9. McLemore EC, Leland H, Devaraj B et al (2013) Transanal endoscopic surgical proctectomy for proctitis case series report: diversion, radiation, ulcerative colitis, and Crohn's disease. Glob J Gastroenterol Hepatol 1:51-57

10. Zorron R, Phillips HN, Coelho D, Flach L, Lemos FB, Vassallo RC (2012) Perirectal NOTES access: "down-to-up" total mesorectal excision for rectal cancer. Surg Innov 19:11-19

11. Sylla P, Rattner DW, Delgado S, Lacy AM (2010) NOTES transanal rectal cancer resection using transanal endoscopic microsurgery and laparoscopic assistance. Surg Endosc 24:1205-1210

12. Rouanet P, Mourregot A, Azar CC et al (2013) Transanal endoscopic proctectomy: an innovative procedure for difficult resection of rectal tumors in men with narrow pelvis. Dis Colon Rectum 56:408-415

13. Velthuis S, van den Boezem PB, van der Peet DL, Cuesta MA, Sietses C (2013) Feasibility study of transanal total mesorectal excision. Br J Surg 100:828-831 (discussion 831)

14. de Lacy AM, Rattner DW, Adelsdorfer C et al (2013) Transanal natural orifice transluminal endoscopic surgery (NOTES) rectal resection: "down-to-up" total mesorectal excision (TME)-shortterm outcomes in the first 20 cases. Surg Endosc 27:3165-3172

15. Atallah S, Albert M, DeBeche-Adams T, Larach S (2013) Transanal minimally invasive surgery (TAMIS): applications beyond local excision. Tech Coloproctol 17:239-243

16. Jorge JM, Wexner SD (1993) Etiology and management of fecal incontinence. Dis Colon Rectum 36(1):77-97

17. McLemore EC, Coker A, Jacobsen G, Talamini MA, Horgan S (2012) eTAMIS: endoscopic visualization for transanal minimally invasive surgery. Surg Endosc 27:1842-1845

18. Cantero R, Salgado G (2012) Transanal access for rectal tumors: the simultaneous use of a flexible endoscope and SILS. Tech Coloproctol. doi:10.1007/s10151-012-0916-4

19. Atallah SB, Albert MR, DeBeche-Adams TH, Larach SW (2011) Robotic transanal minimally invasive surgery in a cadaveric model. Tech Coloproctol 15:461-464

20. Hompes R, Rauh SM, Hagen ME, Mortensen NJ (2012) Preclinical cadaveric study of transanal endoscopic da Vinci ${ }^{\circledR}$ surgery. Br J Surg 99:1144-1148

21. Atallah S, Parra-Davila E, DeBeche-Adams T, Albert M, Larach $S$ (2012) Excision of a rectal neoplasm using robotic transanal surgery (RTS): a description of the technique. Tech Coloproctol 16:389-392

22. Bardakcioglu O (2013) Robotic transanal access surgery. Surg Endosc 27:1407-1409

23. Valls FV, Bassany EE, Jiménez-Gómez LM, Chavarría JR, Carrasco MA (2013) Robotic transanal endoscopic microsurgery in benign rectal tumour. J Robotic Surg. doi:10.1007/s11701-0130429-9

24. Atallah S, Nassif G, Polavarapu H et al (2013) Robotic-assisted transanal surgery for total mesorectal excision (RATS-TME): a description of a novel surgical approach with video demonstration. Tech Coloproctol 17:441-447

25. Atallah S (2013) Transanal minimally invasive surgery for total mesorectal excision. Minim Invasive Ther Allied Technol. PMID:23992386

26. Emhoff IA, Lee GC, Sylla P (2013) Transanal colorectal resection using natural orifice translumenal endoscopic surgery (NOTES). Dig Endosc. doi:10.1111/den.12157

27. Nagtegaal ID, van de Velde CJ, van der Worp E, Kapiteijn E, Quirke P, van Krieken JH (2002) Macroscopic evaluation of rectal cancer resection specimen: clinical significance of the pathologist in quality control. J Clin Oncol 1:1729-1734

28. Jayne DG, Guillou PJ, Thorpe H et al UK MRC CLASICC Trial Group (2007) Randomized trial of laparoscopic-assisted resection of colorectal carcinoma: 3-year results of the UK MRC CLASICC Trial Group. J Clin Oncol 20:3061

29. Kapiteijn E, Marijnen CA, Nagtegaal ID, Dutch Colorectal Cancer Group (2001) Preoperative radiotherapy combined with total mesorectal excision for resectable rectal cancer. $\mathrm{N}$ Engl J Med 30:638-646

30. Nagtegaal ID, van de Velde CJ, Marijnen CA et al (2005) Low rectal cancer: a call for a change of approach in abdominoperineal resection. J Clin Oncol 20:9257-9264

31. Nagtegaal ID, Marijnen CA, Kranenbarg EK et al (2002) Circumferential margin involvement is still an important predictor of local recurrence in rectal carcinoma: not one millimeter but two millimeters is the limit. Am J Surg Pathol 26:350-357

32. Cecil TD, Sexton R, Moran BJ et al (2004) Total mesorectal excision results in low local recurrence rates in lymph node positive rectal cancer. Dis Colon Rectum 47:1145-1149; discussion 1149-1150

33. Wang C, Zhou ZG, Wang Z et al (2005) Mesorectal spread and micrometastasis of rectal cancer studied with large slice technique and tissue microarray. J Surg Oncol 91167-91172

34. Marks JH, Valsdottir EB, Rather AA, Nweze IC, Newman DA, Chernick MR (2010) Fewer than 12 lymph nodes can be expected in a surgical specimen after high-dose chemoradiation therapy for rectal cancer. Dis Colon Rectum 53:1023-1029

35. Wichmann MW, Müller C, Meyer G et al (2002) Effect of preoperative radiochemotherapy on lymph node retrieval after resection of rectal cancer. Arch Surg 137:206-210

36. Faerden AE, Naimy N, Wiik P et al (2005) Total mesorectal excision for rectal cancer: difference in outcome for low and high rectal cancer. Dis Colon Rectum 48:2224-2231

37. Lee SH, Hernandez de Anda E, Finne CO, Madoff RD, GarciaAguilar J (2005) The effect of circumferential tumor location in clinical outcomes of rectal cancer patients treated with total mesorectal excision. Dis Colon Rectum 48:2249-2257

38. Law WL, Chu KW (2004) Anterior resection for rectal cancer with mesorectal excision: a prospective evaluation of 622 patients. Ann Surg 240:260-268

39. Han Y, He YG, Zhang HB et al (2013) Total laparoscopic sigmoid and rectal surgery in combination with transanal endoscopic microsurgery: a preliminary evaluation in China. Surg Endosc $27: 518-524$ 